\title{
RISK PERCEPTION AND VULNERABILITY OF VALUE: A STUDY IN THE CONTEXT OF COMMERCIAL PROPERTY SECTOR
}

\author{
Namrata BHATTACHARYA-MIS ${ }^{\text {a,*, Jessica LAMOND a }}$ \\ ${ }^{a}$ Centre of Floods Communities and Resilience, Faculty of Environment and Technology, Frenchay \\ Campus, University of West of England, Bristol, UK
}

Received 23 March 2015; accepted 30 November 2015

\begin{abstract}
The research was developed linking the impact of flood risk on utility, desirability and marketability related to vulnerability of commercial property value. Likert style questionnaire survey was conducted to obtain data from flood affected and un-affected respondents across different designated flood risk zones on key business and perception variables among two groups of business property holders in England. The responses were analysed through a spatial vulnerability model to illustrate the distribution of the vulnerability of value of properties among flood plain business holders on a GIS platform. Majority of respondents perceived that utility of properties may be hampered by flooding and subsequently have an impact on value for property at risk. Those with flood experience gave greater weight to their specific business needs such as the prime location and expected income level than those without flood experience. The implication of the study lies in understanding that flood risk perceptions can shape actions of people at risk towards future increase in resilience having strategic impact on value of property saleability in the future.
\end{abstract}

KEYWORDS: Risk perception; Vulnerability of value; Spatial vulnerability model; Geographic Information System (GIS); Flood risk

\section{INTRODUCTION}

Changing value of property due to detrimental environmental conditions can be a major concern for property holders (Mundy 1990; Lamond 2008). Flooding is one such environmental hazard that has the potential to have a significant impact on the value of properties at risk (Horn, McShane 2013). The economic impact of flooding has received increased attention in the scientific community owing to the prospect of several projections of changing magnitude and frequency of flooding in future (Evans et al. 2008; IPCC 2012). The prime concern is that the value of a property can be affected directly by physical impact of flooding or indirectly by the social, economic and political assumptions associated with the condition of the assets at risk (RICS 2011, 2012). This is especially important for properties within the commercial sector that are susceptible to initial business interruption and closure caused by flood events and the lingering effect of stigma potentially affecting property value (Vatsa 2004; Wedawatta et al. 2010; Mundy 1992).

\footnotetext{
* Corresponding author. E-mail: Namrata.Bhattacharya-Mis@uwe.ac.uk
}

The commercial property sector is a central component of national assets, and business operating from within this sector contributes heavily to Gross Domestic Product (GDP). Therefore value of commercial property is of significance to direct property stakeholders and to local and national economic prosperity (British Property Foundation 2014). Within the UK, the contribution of commercial property sector forms a significant portion of the economy. While the market value of core commercial properties in the UK which includes retail, office and industrial properties, according to Property Data Report in 2013 is £683 Billion (British Property Foundation 2014) risk analysis firm Maplecroft reported in 2014 that UK ranks $7^{\text {th }}$ highest among 197 countries assessed in terms of economic exposure to flooding (Nichols 2014). With approximately 185,000 commercial properties at risk and the level of associated vulnerability, there is clearly a need to investigate the potential impact of flooding on the commercial property sector (Environment Agency 2009). This

Copyright (C) 2016 The Author(s). Published by Vilnius Gediminas Technical University (VGTU) Press, and Taylor \& Francis. This is an Open Access article distributed under the terms of the Creative Commons Attribution-NonCommercial-NoDerivatives Licence

(http://creativecommons.org/licenses/by-nc-nd/4.0/), which permits non-commercial re-use, distribution, and reproduction in any medium, provided the original work is properly cited, and is not altered, transformed, or built upon in any way. http://www tandfonline com/TSPM 
is recognised that the assessment of the potential exposure and loss in value of the existing assets is a crucial component in plans for loss avoidance and increasing resilience in future (Rose, Krausmann 2013). Despite the importance of the commercial sector to the national economy, many of the research studies in the last decade in the context of flood risk management are either partly or fully focused on residential property sector (Kenney et al. 2006; Koerth et al.2013; Lamond 2008) with few exceptions such as studies on small and medium industries (Wedawatta 2013) and measuring economic framework for resilience of businesses (Rose, Krausmann 2013). Integrated flood risk management research in the last two decades have incorporated the concept of vulnerability of flood affected communities to various impacts including physical and social effects including risk perception (Bubeck et al. 2012; Adger 2006; Cutter 1996). In a commercial property context, vulnerability of property value towards flooding can include business vulnerability as a result of direct and indirect impacts of previous floods; and perception of vulnerability in peoples' minds as response to their previous flood experiences. Valuation research particularly that relating to environmental conditions is often focussed on market based empirical studies measuring changes in market price as a proxy for value of property (Connellan 1998; Debrezion 2007; Gatzlaff et al. 2015). This approach, emerging from economic theory of Rosen (1974), is limited in its ability to inform policy and practice in rapidly evolving hazard scenarios particularly in suggesting actions to mitigate future impacts.

The current investigation is situated between two domains of research: flood risk management and real estate valuation. Empirical market price measurement was eschewed for multiple reasons. The feasibility and quality of empirical research into the effect of environmental input on the output of economics of real estate value depends heavily upon access to comprehensive and disaggregated data. As Byrne (2005) and Fuerst et al. (2011) indicated, despite several agencies holding data for aggregated market trend and index purposes, this data is not available or sufficient for the analysis of individual locations, especially for detailed and specific environmental studies in the context of commercial properties. Research also suggests that even when data is available the impact of flooding on market value is difficult to assess from the current market due to causes such as imperfect information, risk perception and differences in availability of insurance (Lamond et al.
2010). However over time as information improves, risk changes, risk perception shifts and insurance availability declines, it is expected that the locations which are considered to be more secure will be more desirable and less economically vulnerable (Pottinger et al. 2011). The focus of the study is to anticipate the effect flood risks have on commercial property holders' perception on vulnerability of value of property rather than an attempt to measure the historical impact of flooding in the commercial market to date. In this paper property means commercial properties unless otherwise stated.

\section{THE PRESENT STUDY: AIMS, OBJECTIVES AND RATIONALE}

In the context of this study vulnerability of value can be introduced as the interplay between different physical, social, economic and environmental vulnerabilities and their subsequent outcome in disruption of commercial property utility, desirability and marketability. Vulnerability of value for the context of this study can be described as the relationship between the potential exposure of the total value of a commercial property to a given magnitude of flood risk with its internal and external sensitivity and capacity to overcome and recover from the disruption to restore original condition in the market. To understand the relationship between perception towards flood risk and vulnerability of value it is important to understand the meaning of the word perception in general and towards flood risk in particular. Several views were identified in literature regarding perception. Development in the field of cognitive and emotional psychology introduced perception as a process which is complex and can encompass both cognitive and affective aspects of responses (Forgas 2003; Slovic et al. 2004). Such responses can serve as prompts for future probability judgements. Risk perception can be considered as the evaluation of probability of future event causing loss to personal and material damage (Miceli et al. 2008). However, there is a general lack of understanding in the real estate research field where emotional and cognitive aspects of related stakeholders are hardly taken into account for understanding probability of changes in future property value.

Market perception is the reflection which is the basis of interaction between usability, desirability and marketability of the property which in turn indicates the vulnerability of value. Such knowledge is useful for property valuers to evaluate property 
based on the local knowledge and understanding. It is possible that the impact flooding on people's mind especially if it happens repeatedly can generate specific perception towards future change in property value. The usability of property includes factors associated with the physical and economic characteristics of property and the extent and nature of risk exposure having an impact on the property utility. Desirability of property on the other hand involves factors that can make a property more attractive for buyers or renters in the market. This can be with reference to history of flood risk and level of adaptability of the property in risk reduction. Finally marketability of property is determined by how the buyers or investors perceive the property for future investment by determining a balance between risk and profitability. The prediction is that market perception can have significant impact on changing the way property value is understood in the future. The aim is to understand how change in perception of flood risk and vulnerability can have an impact in changing behavioural pattern towards property value in commercial property sector.

\section{METHODOLOGY}

\subsection{Research site and sample}

The measurement of market perception in the present study is based on a questionnaire survey and is aimed at investigating vulnerability of property value towards flood risk based on the perception of commercial property holders (both owners and lease holders) in two areas in the county of North Yorkshire in the UK. A survey was conducted to capture geographically scattered respondents from medium and high flood risk areas as there is a lack of existing data in this field. The understanding of perception of commercial property sector population is varied in space and time. Therefore to capture the view of the geographically spread previously flooded and non-flooded sample population (commercial property holders in this case) of varying exposure in a cost effective manner, survey was undertaken by use of a postal questionnaire.

Three factors were taken into account while selecting the study areas: history of flooding in the area, present risk of flooding and number of commercial properties affected by flooding in the most recent flood. The national assessment of flood risk England states that the second area, after London, at highest risk of flooding with largest number of people living at risk is Yorkshire and Humber region in England (Environment Agency 2009). The number of commercial properties affected by the 2007 flood in the region was approximately 3718 which is the highest in the entire country (Environment Agency 2009). Within North Yorkshire the two selected study areas are Sheffield and Wakefield. Both these areas have past history of frequent flooding and are currently exposed to high levels of flood risk (see Appendix 1 for detailed division of levels of likelihood of flooding delineated by Environment Agency). In Wakefield a census sample was selected in flood zone 2 and 3 for the five postcode zones most affected by flooding while in the lower risk region (Flood zone 1) an equal number of properties were selected (randomly) from the population to have a comparative view of perception from flooded and non-flooded population. Total sample size in each area was 1830. Wakefield in Calder Valley has about 794 commercial properties at potential risk of flooding based on the 2007 flood event (JBA Consultant 2009). In Sheffield approximately 1000 businesses were flooded in the 2007 flood event (JACOBS 2008). Two postcodes that were seriously affected by 2007 flood event were selected for questionnaire distribution. The same number (1830) of questionnaires as Wakefield were circulated among Environment Agency delineated flood zones 1, 2, and 3 for representative sampling in all risk zones.

\subsection{Measures}

The study is grounded in understanding vulnerability of value dependent on the perception of commercial property holders towards flood risk. Therefore the requirement was to collect data associated with the market perception of respondents. The postal questionnaire consists of three sections:

- nature and experience of flooding, impact and recovery measures taken for risk reduction,

- perceptions on flooding and its impact on vulnerability of property value (involving property usability, desirability and marketability indicators),

- demographic information related to the business and ownership of property.

The section related to perception data is the main focus of the analysis in this paper. The collected data is a combination of existing secondary data related to flood risk status of the selected study areas collected from Environment Agency and primary data related to flood experience, its impact and perception collected from respondents 
through postal questionnaire. Direct measurement of all variables associated with perception of people was not possible therefore indirect techniques such as use of Likert scale to understand the preference of respondents was adopted (Oppenheim 1992; Creswell 2009). Market perception of commercial property holders was investigated using a 16 item (statements) perception profile. The statements correspond to the effect of flooding on property usability, their desirability and attractiveness in the real estate market on a Likert scale agreement range of 1 to 5 where 1 indicates strong disagreement, 3 shows neutral attitude and 5 reflects strong agreement with the respective statement (see Appendix 2). Figure 1 discussed in section 3.4 indicates the spatial vulnerability model based on the sixteen statements used in the questionnaire, derived from a conceptual framework based on literature. The questionnaire was intended to study a wide variety of issues related to hydrological risk derived from both flood experienced and inexperienced respondents to gain a variation in the perception. The intention was also to identify whether the perception of people with experience of flooding differs from those having no previous flood experience.

\subsection{Exploratory data analysis and validation of perception scores}

Descriptive statistical analysis on the quantitative data collected through questionnaire survey was undertaken. Data exploration was important for understanding the suitability of the collected perception data for the purpose of next stages of vulnerability of value analysis. Due to the asymmetric nature of the data median values of agreement instead of mean average values from the perception statements were used to represent central value. The data was identified by commercial property occupier's agreement analysis to respective value of perception statements. It was however important to have an evidence of the nature of consistency among raters (participants providing agreements for specific perception criteria) to see whether the selected median values representing the different criterion can be interpreted for further analysis of vulnerability of value with confidence.

Measurement of the agreement among the respondents was required to demonstrate the responses obtained are more similar to each other than would be expected by chance (Klein et al. 1994). The degree to which ratings are similar in level and magnitude within a group is determined by the inter-rater agreement $\left(\mathrm{r}_{\mathrm{WG}}\right)$ technique. The ensuing equation (1) used for the agreement index is:

$$
\mathrm{r}_{\mathrm{WG}}=1-\frac{\mathrm{S}_{\mathrm{x}}^{2}}{\sigma_{\mathrm{E}}^{2}},
$$

where: $\mathrm{S}^{2}$ - observed variance in ratings; $\sigma^{2}$ - variance of null; 1 - perfect agreement; 0 - absence of agreement.

The interpretation of $r_{\mathrm{WG}}$ as greater than $>0.7$ was conventionally considered to be representative of good agreement (James et al. 1993). Nevertheless, later researchers indicated that the rule of thumb that $r_{\mathrm{WG}}$ that exceed $>0.7$ does not always perform as a good indicator of agreement because this value varies substantially according to sample size of rater group (Cohen et al. 2001). Therefore the interpretation based on sample size of the present research is undertaken for agreement analysis. $\mathrm{R}$ statistical software package was used to calculate the $r_{\mathrm{WG}}$. After the agreement analysis was undertaken the criteria were set for analysis of vulnerability of value through spatial vulnerability model of perception using Geographic Information System (GIS) platform.

\subsection{Spatial vulnerability model of perception}

Spatial ranking approach using collected perception data was adopted for mapping vulnerability. GIS was used to undertake the mapping of theoretical determinants of vulnerability in an effort to illustrate spatial distribution of differential capacities and exposures of risk of flooding in the two geographically diverse locations. To interpret the vulnerability and spatial interrelationship between different socio-economic and physical determinants it is essential to highlight the importance of spatial scale as the 'weight and relevance' of dynamic elements of vulnerability assessment changes with changing spatial scale (Eakin 2006). It should also be pointed out that there might be abrupt changes in level of vulnerability as a result of changes in scale and data integration rather than smooth transition as it would be expected (O'Brien et al. 2004). The spatial distribution of vulnerability of value was based on the pre-generated GIS layers from collected responses on perception of property usability, desirability and marketability. Figure 1 indicates the setup of the spatial vulnerability model. The model illustrates three levels of mapping vulnerability based on collected primary and secondary data using spatial ranking. The first level (level 1 in the Figure 1) indicates how layers of perception 


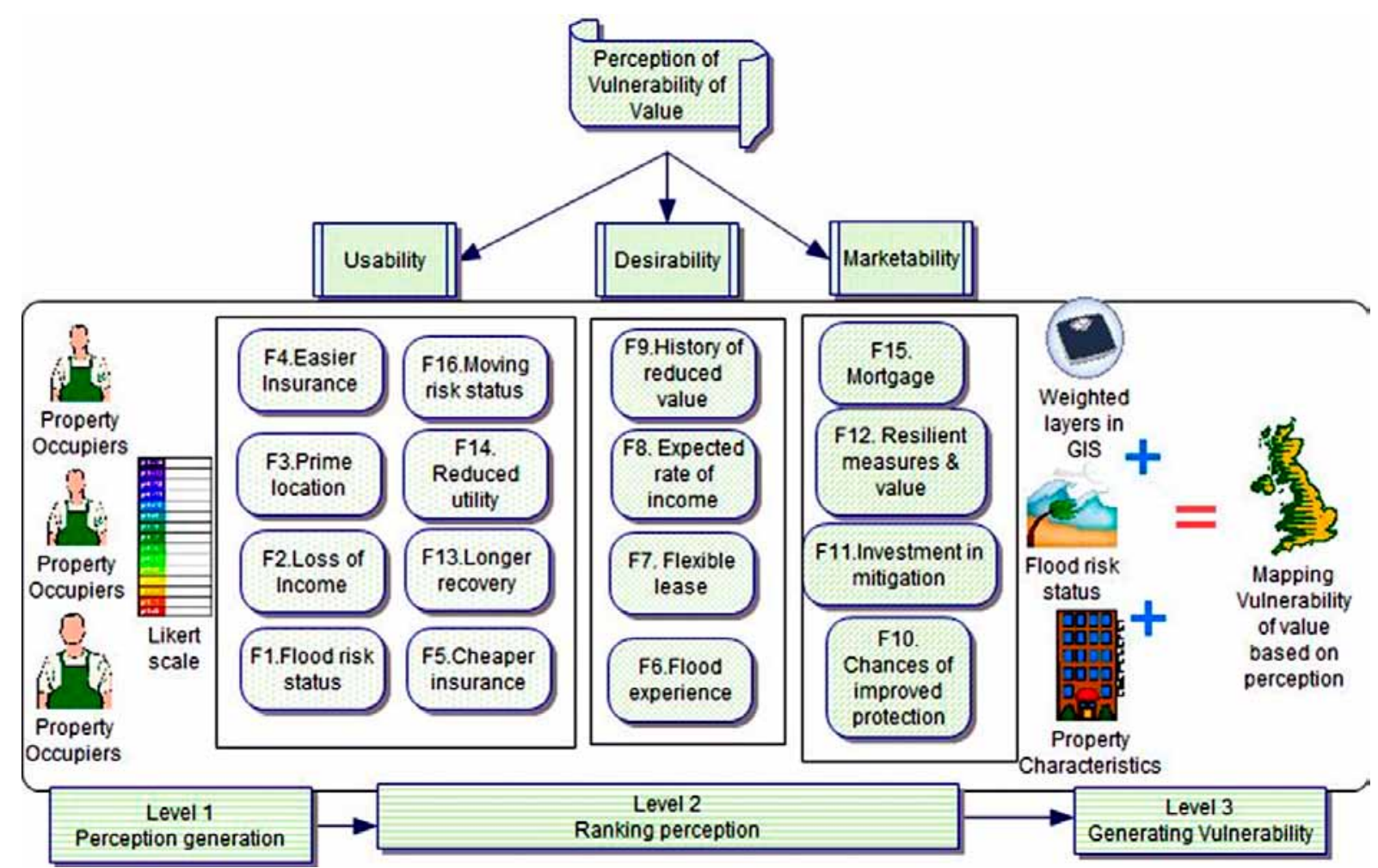

Fig. 1. Spatial ranking model for deriving vulnerability of value of commercial properties based on flood risk perception

were generated using data accumulated through responses (utility, desirability and marketability) from the sample areas. Perception information obtained from the survey is then ranked according to their importance indicated by respondents. The generated values were then added as spatial layers. This is indicated by level 2 in Figure 1. Based on the criteria and the ranks associated with the respondents' perception, the primary task was to prepare a vulnerability summary table (VST). Once the weighted layers were generated, they were overlaid by associated factors such as existing flood risk status of the area and characteristics of commercial properties affecting vulnerability of value to generate the final layer indicating differential vulnerability. Since vulnerability is a predictive characteristic it was important to understand the condition of businesses may predispose them to harm from sudden disruption such as flooding. Such understanding was expected to be obtained from the respondent's past experiences of flooding. The following section will illustrate how the different criteria were ranked to generate the integrated layers for spatially distributed vulnerability maps.

\subsection{Criteria ranking}

Ranks (used for weighting variables) help in determining the importance of one criterion in relation to others. In the context of this study, importance could be based on characteristics of property, exposure or the perception of property holders towards flood risk. Literature emphasized that assignment of weights should be the reflection of public perception or experience rather than the views of a few experts (Raaijmakers et al. 2008). Researchers in the field of climate change and disaster management advocate for incorporation of stakeholders input along with expert knowledge to address the inherent uncertainties of socio-economic aspects (United Nations 2015; O'Brien et al. 2004). The strength of this technique lies in its ability to combine information from various scientific fields which have been successfully validated and are necessary for studies incorporating human-environment interaction. Ranks were derived directly from the analysis of survey questionnaire where respondents indicated their choices through the given Likert scale. Median value of perception ranks were used for ranking individual properties. Criteria such as property characteristics and type of exposure collected from the questionnaire were assigned ranks based on the responses of flood experienced commercial property holders and available data from the Environment Agency flood maps. Factors affecting perception are ranked based on the values assigned to the Likert scale (5 point) 


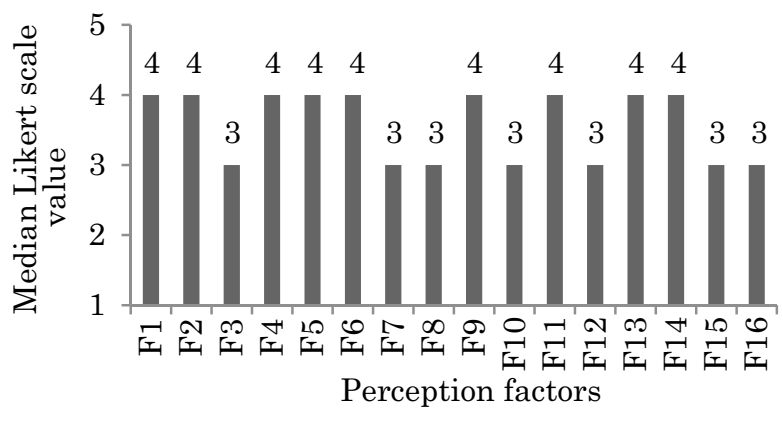

Fig. 2. Median perceptions of flood plain commercial property respondents

by all respondents. Any average agreement level over 3 (neutral) is considered to be part of higher agreement and vice versa. These values were then weighted and ranked accordingly. As a result of the assignment of scores each specification of perception now has individual score within its attribute sets. The total aggregated score obtained for each sub-criterion was then normalized into a dimensionless effect score between 0 and 1 . This is a usual choice for the domain of vulnerability assessment in disaster studies (Cutter et al. 2009). With perception of higher vulnerability of value, highest weight of 1 is assigned, followed by neutral agreements of 0.5 and 0 for lower agreements. Table 1 in the results section shows the weights of different layers for analysis of vulnerability of value based on respondents' perception of property utility, desirability and marketability. The final ranks were then formatted to be integrated with GIS layers as discussed in section 3.4. Values were assigned to postcode sub-area level based on the commercial property characteristics and flood risk status to generate spatially distributed vulnerability of value maps towards flood risk.

\section{RESULTS}

The value of inter-rater agreement $\left(\mathrm{r}_{\mathrm{WG}}\right)$ for respondents in Wakefield are 0.11, 0.14 and 0.19 at the $90 \%, 95 \%$ \& $99 \%$ confidence interval estimated respectively for group size 102 with 5 response options (5 point scale). Hence $r_{\mathrm{WG}}$ values $>0.19$ are evidence of significant agreement at $p$ $<0.01$. Based on the same rule, values among responses from Sheffield were also consistent within the group size. In Sheffield single-item inter-rater agreement index $\left(\mathrm{r}_{\mathrm{WG}}\right)$ values of $0.10,0.13 \& 0.18$ are the $90 \%, 95 \%$ \& $99 \%$ confidence interval estimates respectively for group size of 111 and 5 response options. Hence $\mathrm{r}_{\mathrm{WG}}$ values $>0.18$ are evidence of significant agreement at $\mathrm{p}<0.01$.

\subsection{Perception of flood risk towards vulnerability of value}

Out of 1830 questionnaires distributed in Wakefield 148 returned among which 102 were suitable for analysis. In case of Sheffield the numbers are 152 returned and 111 were usable for further analysis. Missing data in responses involving demography, flood status and perception related information were observed, as a result relationships between respondents of particular type (for example flooded or non-flooded) could not be made. Given that no incentive is provided to the respondents and the survey was (necessarily) quite lengthy such issues are to be expected. The usable sample of over 200 responses is distributed among all flood risk zones indicate that bias due to non-response is minimal. The received response from different zones shows that the distribution of the sample response was well balanced across different flood risk zones and good enough to avoid subsequent data bias. An overall assessment of perception data was undertaken by analysing measures of central tendency. This helped in identifying the spread and distribution of perception data among all flooded and nonflooded respondents. The average perceptions of commercial property holders towards vulnerability of flooding to property value are shown in Figure 2 (see reference F1-F16 in Figure 1).

The average perception of all commercial property respondents irrespective of their flood experience showed a fairly neutral attitude towards vulnerability of value in terms of locational aspects (F3), flexible lease terms (F7), higher expected income and high demand for properties (F8). Neutral attitude can also be observed for aspects like historical reduction of property value as a result of flooding (F10), installation of flood protection measures (F12), easy mortgage availability (F15) or high risk of flooding and desirability to move out (F16) of the high risk zones in the flood plain. A possible reason behind the neutral opinion of property holders that businesses at high risk of flooding would not want to move to safer location (F16) may be due to the closeness to suppliers or existing customer base. It is also possible that there is lack of knowledge of the potential risk of flooding. The average neutrality of respondents with respect to prime location (F3) of properties and their relationship with usability and resultant marketability against flood risk was observed. Prime location is indicated as important by manufacturing, leisure and entertainment sectors however a higher number of other sectors showed neutral attitude 
towards its impact on property value; therefore on an average the attitude towards prime location is shown by neutral value. Loss of income from high flood risk (F1) was given higher average agreement indicating the existing knowledge that flood risk can expose businesses conducted by commercial properties to the risk of significant loss of income (F13) and cause them to lose value (F2) in the long run. Property holders also recognized the importance of lower income due to longer recovery time and consequent low value of the property, impact of historical floods (F6), opportunities involved in obtaining easy and cheap insurance (F4, F5), improving protection of the property (F9, F11) and effect of low income on the utility of property (F14). All these factors were generated from the median value of perception from all respondents. It is now also important to understand whether there are any differences of perception between the flooded and non-flooded population for the same perception issues. The following section will compare between flooded and non-flooded responses in terms of their general agreement and inter-rater agreement to the perception factors.

\subsection{Perception of flooded and non-flooded population}

Observing the agreement of perception and the inter-rater agreements among flooded and non-flooded commercial property holders', slight differences can be observed in Figure 3. As discussed in section 4 the rates of inter-rater agreement among all respondents were significant in all cases of flood affected and unaffected population. The sample size has an impact on the agreement level; there are 69 flood affected respondents against 231 non-flooded respondents, therefore higher agreement between the smaller samples is more remarkable. In the previous discussion it was mentioned that neutral attitude was observed among respondents towards the factor of prime location (F3). It can be observed here in Figure 3 (top) where respondents with experience of flooding showed higher agreement towards the importance of prime location over flood risk than their non-flooded counterparts. The $\mathrm{r}_{\mathrm{WG}}$ score for F3 also shows that the view is consistent among flooded respondents. Similarly, it was observed in Figure 2 that, on average, perception of respondent's matches with the importance of investing in mitigation activities for risk reduction (F11) however there was neutral attitude towards such changes in demand for longer term (F12). The difference in attitude could be observed (F9)
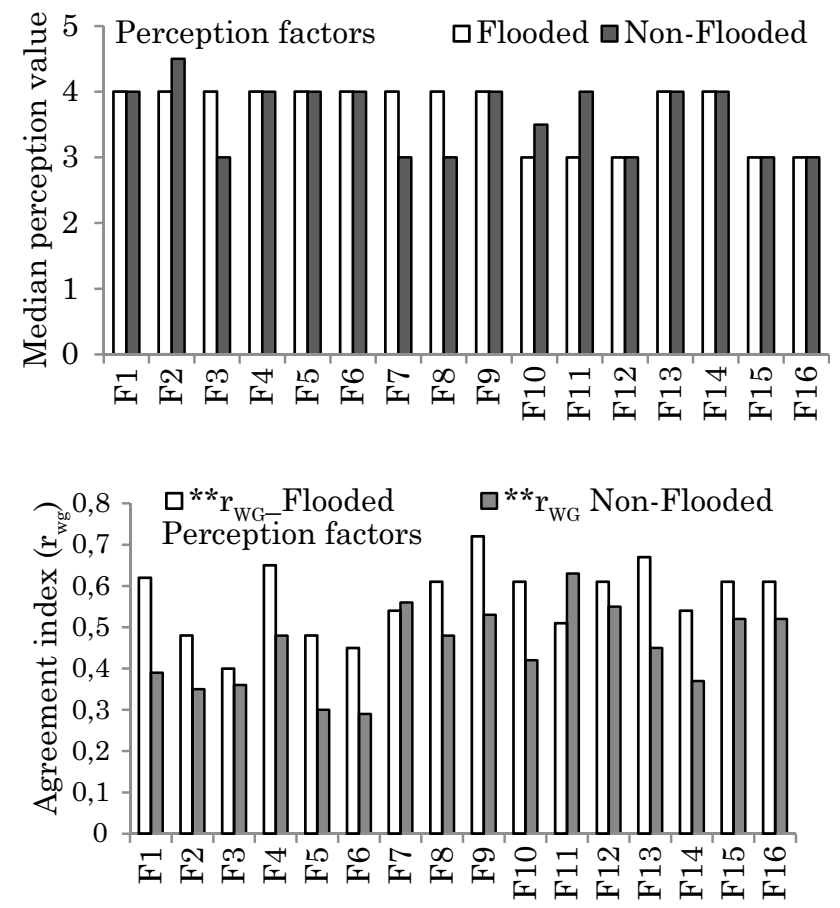

Fig. 3. Observed agreement (top) and $r_{\mathrm{WG}}$ (bottom) difference between flood affected and non-affected respondents

in the context of demand for property in the real estate market in the future by investing in mitigation and preparedness measures against flooding between flooded and non-flooded respondents. Interestingly, when the $r_{\mathrm{WG}}$ score is observed for the statement improved protection against flooding may provide higher value in property market (F9) the flood affected respondents' showed comparatively higher consistency among themselves than the non-flooded respondents. Evidence from literature suggest that with increased experience of flooding the affected population tend to be more prepared (Bhattacharya-Mis et al. 2015; Kreibich 2007). However the flood experienced population seems to indicate that there is a short term relationship between preparedness measures against future floods and marketability of property (F12). The view shows consistency among the flood affected and unaffected population. Understanding the situation that people go through when there is a flood event differs between those with actual experience from those who have no previous experience of flooding. There is apparently added concern and confusion among non-flooded respondents due to inexperience. Having discussed the characteristics of responses, the following section will explain the model based on the weights derived from these responses and describe the spatial vulnerability distribution in the study areas. 


\subsection{Spatial modelling in GIS}

Using the standardized weights shown in Table 1 obtained from respondents of different property types, individual properties were assigned ranks on the basis of their business characteristics, type of preparedness, level of protection and existing flood risk status to assess vulnerability of value based on perception data as indicated by the spatial ranking model in Figure 1.

The weights (between 0 and 1 ) are indicators of how respondents in the market actually perceive the properties with specific characteristics located within certain flood risk zones. The vulnerability of value spatial layer was generated using ARCGIS 10 software. Vulnerability levels were then averaged at a postcode level to provide an illustration of the distribution of market perception of vulnerability of property value to specific flood risk. The final spatial vulnerability maps indicate the distribution of vulnerability of value at selected postcode level in both Wakefield and Sheffield.

The output from the spatial vulnerability of value analysis can be interpreted as representation of spatial variation of the vulnerability of value of property. The vulnerability is based on the existing exposure to flood risk and the perception of occupants within different risk zones towards that risk. The following section will elaborate on the spatial distribution of vulnerability of value maps and discuss the common features of vulnerability of value in the two selected study areas.

\section{DISCUSSION}

The two maps for selected areas of Wakefield and Sheffield shown in Figure 4 indicate vulnerability of value levels in traffic signal colour scheme. The green patches indicate low vulnerability; yellow patches show medium vulnerability and red patches display high vulnerability of value towards floods. It is visible from the distribution of vulnerability of value that direct delineation of fluvial flood risk is defining the vulnerability zones associated to Environment Agency flood risk maps. Observation of spatial distribution of vulnerability in both regions reveal that medium and high vulnerability of value zones are mainly spread across medium and significant flood risk zones (Environment Agency's flood zone 2 and 3). This distribution is also reflected from the perception of respondents whose properties are located at high and medium risk of fluvial flooding. The general perception was that they will experience more loss of income as a result of frequent flooding in the area and subsequently the property will lose demand in the real estate market. Properties at high risk zones are prone to direct damage and disruption, therefore loss of income is expected to be higher and recovery time will be longer than properties in low risk zones. Loss of demand in the market can make the value of these properties vulnerable in future.

According to the perception of the respondents, properties which have cheap and easy access to in-

Table 1. Vulnerability summary table (VST) illustrating weights associated with perceptions

\begin{tabular}{lll}
\hline Index & Median & Weight \\
\hline F1: Higher risk lower income & 4 & 1 \\
F2: Lower income lower value & 4 & 1 \\
F3: Prime location high value & 3 & 0.5 \\
F4: Easy insurance high value & 4 & 1 \\
F5: Cheap insurance high value & 4 & 1 \\
F6: Historical flood low value & 4 & 1 \\
F7: Flexible lease higher desirability & 3 & 0.5 \\
F8: Higher expected income high demand & 3 & 0.5 \\
F9: Higher protection high value & 4 & 1 \\
F10: Historical low value and low demand & 3 & 0.5 \\
F11: Higher mitigation high demand & 4 & 1 \\
F12: Lowering risk has no long term effect & 3 & 0.5 \\
F13: Higher loss in income longer recovery & 4 & 1 \\
F14: Longer recovery lower utility & 4 & 1 \\
F15: Easy mortgage high demand & 3 & 0.5 \\
F16: High risk low desirability to stay & 3 & 0.5
\end{tabular}

Highest weight of 1 is assigned for highest agreement, followed by neutral agreements of 0.5 and 0 for lower agreements of perception for vulnerability of value 

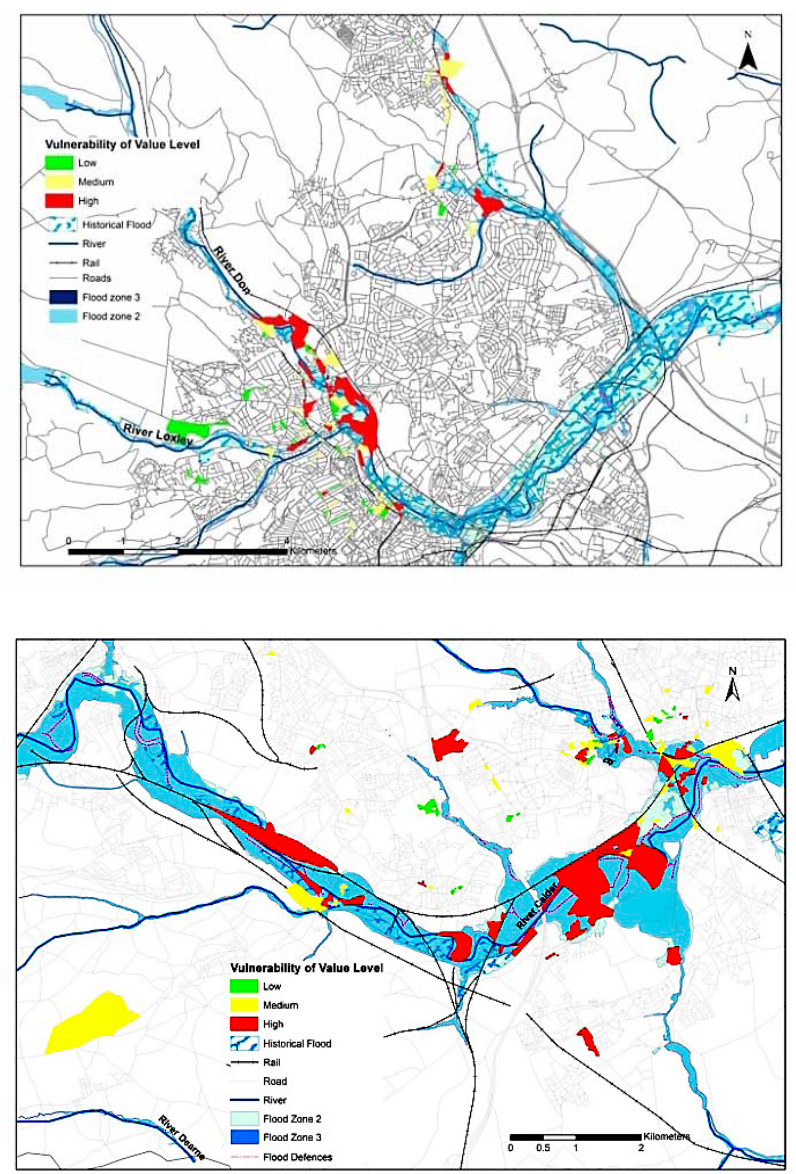

Fig. 4. Spatial distribution of Vulnerability of value in selected postcodes of Wakefield (top) and Sheffield (bottom)

surance are more desirable in the real estate market. Therefore, those properties having insurance were included under lower vulnerability weights as these properties are expected to reduce their recovery cost and time in in case of future flood event. Properties without flood insurance are assigned a higher vulnerability of value status in the model. Furthermore, areas with history of flooding are shown as more vulnerable to value than others due to the existing stigma of historical flood memory in the system. Respondents perceive that properties with history of flooding or flood related renegotiations in value may find it hard to recover in the market. Therefore their values are considered to be permanently affected and more vulnerable to changes. The statements informing the perception of property usability, desirability and marketability are accessed through subjective probability judgements of risk likelihood. The intention was to identify causes of changing property value in future. No clear evidence or direct link was found between high flood risk and property value in the market. However based on the risk perception of respondents, high risk of flooding may prove to be one of the causes of change in property value temporarily. Therefore the values of properties at low risk of flooding are shown as less vulnerable. Some properties were affected by higher levels of indirect disruption and longer recovery times, however commercial property holders' perceive those properties are not going to lose their value in the future because they do not have any history of direct flooding and are affected by indirect impacts. Such impacts are thought to be for short term and have potential to recover sooner from the effect of temporary indirect disruptive phenomenon. As a result, the value of properties affected by indirect impacts is not considered to be as vulnerable as those directly affected by historical floods. Majority of the respondents agree that investing in mitigation activities may have some positive impact on demand of properties but such demand will not be for long term. Perception suggests expenditure on mitigation means more investment at present with no or little long term return. Therefore values of such properties at high terms, higher expected income, longer recovery time reducing property utility, risk reduction measures are also considered to be vulnerable. The rest of the factors such as prime location, flexible lease and easy mortgage terms are all reflecting neutrality in peoples' perception in relation to property value, therefore these factors are considered to have lower impact on future vulnerability of value.

To summarise, the vulnerability of value which is determined by perception is mostly predicted based on existing exposure to risk status and expected direct impacts. Therefore low level of vulnerability of value mostly corresponds with low level of risk and vice versa. The spatial distribution of commercial property was averaged at postcode level and vulnerability of value towards flooding is illustrated by vulnerability maps for both study areas. In the absence of measurable impact of flooding on the commercial property real estate market, these maps are valuable illustrations for understanding the conceptual outputs from literature and empirical verification through questionnaire enquiry of potential impacts. It is evident from the spatial distribution of vulnerability of value that the direct impacts of flooding are more apparent than indirect effects reflecting lack of experience in the demand population. The illustrations assist in understanding not only the distribution of vulnerability rendering to designated hazard by Environment Agency flood maps but also according to flood risk perception of commer- 
cial property holders. These maps have potential uses in planning property and asset management. Priority based property investment which requires identification and concentration on more vulnerable areas or assisting in valuation of properties based on their level of vulnerability are the other useful avenues of these research outputs. Due to the methodological flexibility similar research can be performed in other geographical areas by making slight changes in the context of specific locational setting. It is also possible to use the research methodology for understanding temporal variation in perception of population for different time periods after disruption takes place. Accurate and reliable evaluation of flood affected properties by surveyors involving an appreciation of factors affecting vulnerability of value is required for appropriate decision making in flood risk reduction (Bhattacharya et al. 2013; Bhattacharya-Mis, Lamond 2014). The role of surveyors is evident when knowledge of the uncertainties in terms of the availability of insurance, adverse impact on capital value and future saleability of the flood affected or at risk property is concerned. Understanding perception of value from commercial property holder's point of view together with the vulnerable situation of properties with flood experience on the ground can be very helpful for valuers in providing informed advice to the flood affected businesses and reduce the amount of assumptions made in valuing properties.

\section{CONCLUSION}

Traditionally, property value research was largely associated with measurable physical and market factors with limited appreciation of perception and behavioural factors. This research has asserted that cognitive factors may not be reflected in current market behaviour but are essential in understanding long term asset performance. Therefore, integrating perception into salient and diverse perspectives of value and assimilating them to produce a unique concept of vulnerability of value is a major contribution to knowledge. The primary theoretical contribution of this research is the coherent conceptualisation of the vulnerability of property value to flood risk and future flooding by incorporating the concept of vulnerability from flood risk management into valuation theory. This has been achieved through assessing the impact of risk on property utility, desirability and marketability. The explicit linking of vulnerability of value of commercial properties in a structured framework is a novel approach that may be applicable beyond the field of flood risk assessment.

The integrative perspective plays a complementary role to existing market based research and provides a complete picture of the system and the various processes of commercial property and its vulnerability towards flood risk. The research has shown that it is possible to investigate the relationships between complex criteria such as flood vulnerability and vulnerability of property value. Using spatial tools such as GIS in the context of property value research offers additionality to such scenario based studies for understanding potential future changes in value spatially. The concepts and methods are generalizable across different geographical and environmental areas. However the measured characteristics of commercial properties and local perceptions are likely to be highly context specific and will require calibration via local surveys if applied in other geographical locations and property markets. The methodology also provides the opportunity to understand the sensitivity of different vulnerability factors towards changing perception of property holders.

In terms of changing practice the study highlights that vulnerability of value is a multi-faceted issue to investigate and it consists of various interrelated factors. Therefore, to make an impact on vulnerability reduction a holistic approach towards understanding vulnerability in market context is required and this research has allowed a more structured understanding of the role that perception may have on market behaviour. The approach is most suitable in situations where market reflection is not easily available, scattered or absent and where changes in risk make direct market measurement inappropriate. It is recognised that the operationalisation was based on knowledge gained from two areas with a limited number of responses and may lack generalisation. However, practitioners may more easily contextualise the findings in the light of their local knowledge and expertise due to the structured framework of analysis. It is recommended that more data from commercial properties in all flood risk zones would improve the granularity of findings and allow for property level vulnerability of value analysis. It would be useful for future research to anticipate the response and recovery strategies of flood affected commercial property holders and the impacts on future floods to understand the changes in the vulnerability of 
value of property in the given areas. Similarly research is needed in different geographical locations with special attention on inclusion of historical floods so that the method of vulnerability of value assessment can be robustly validated and the potential for generalisability across locations can be assessed. The potential for vulnerability of value research to contribute in-depth understanding is demonstrated here in flood risk management but may profitably be explored in other environmental and hazard management scenarios.

\section{ACKNOWLEDGEMENTS}

The research project was funded by University of Wolverhampton. Additional support was provided by University of West of England and EPSRC FloodMEMORY Project. The authors are grateful to Environment Agency for providing GIS based flood risk data.

\section{REFERENCES}

Adger, W. N. 2006. Vulnerability, Global Environmental Change 16(3): 268-281.

http://dx.doi.org/10.1016/j.gloenvcha.2006.02.006

Bhattacharya, N.; Lamond, J.; Proverbs, D.; Hammond, F. N.; Searle, D. 2013. Development of conceptual framework for understanding vulnerability of commercial property values towards flooding, International Journal of Disaster Resilience in Built Environment 4: 334-351. http://dx.doi.org/10.1108/IJDRBE-08-2012-0024

Bhattacharya-Mis, N.; Joseph, R.; Proverbs, D.; Lamond, J. 2015. Grass-root preparedness against potential flood risk among residential and commercial property holders, International Journal of Disaster Resilience in Built Environment 6(1): 44-56. http://dx.doi.org/10.1108/IJDRBE-08-2014-0059

Bhattacharya-Mis, N.; Lamond, J. 2014. Socio-economic complexities of flood memory in building resilience: an overview of research, Procedia Economics and $\mathrm{Fi}$ nance 18: 111-119. http://dx.doi.org/10.1016/S2212 5671(14)00920-4

Bhattacharya-Mis, N.; Lamond, J. 2015. Mapping community knowledge of vulnerability of value: a case study in the UK, International Journal of Safety and Security Engineering 5(3): 266-279. http://dx.doi.org/10.2495/SAFE-V5-N3-266-279

British Property Foundation. 2014. Property data report 2014. London: British Data Foundation.

Bubeck, P.; Botzen, W. J. W.; Aerts, J. C. J. H. 2012. A review of risk perceptions and other factors that influence flood mitigation behavior, Risk Analysis 32(9): 1481-1495.

http://dx.doi.org/10.1111/j.1539-6924.2011.01783.x
Byrne, P. 2005. A geography of the UK commercial property market, Working Papers in Real Estate \& Planning. 17/05. University of Reading, Reading.

Cohen, A.; Doveh, E.; Eick, U. 2001. Statistical properties of the rWG(J) index of agreement, Psychological Methods 6(3): 297-310.

http://dx.doi.org/10.1037/1082-989X.6.3.297

Connellan, O.; James, H. 1998. Forecasting commercial property values in the short term. The Cutting Edge 1998. RICS Research, Dublin.

Creswell, J. W. 2009. Research design qualitative, quantitative and mixed methods approaches. $3^{\text {rd }} \mathrm{Ed}$. London: Sage Publications Ltd.

Cutter, S. L. 1996. Vulnerability to environmental hazards, Progress in Human Geography 20(4): 529-539. http://dx.doi.org/10.1177/030913259602000407

Cutter, S. L.; Emrich, C. T.; Webb, J. J.; Morath, D. 2009. Social vulnerability to climate variability hazards: a review of the literature, Final Report to $O x$ fam America. HVRI, University of South Carolina.

Debrezion, G.; Pels, E.; Rietveld, P. 2007. The impact of railway stations on residential and commercial property value: a meta-analysis, Journal of Real Estate Finance Economics 35(2): 161-180. http://dx.doi.org/10.1007/s11146-007-9032-z

Eakin, H. 2006. Assessing the vulnerability of socio-environmental systems, Annual Review of Environment and Resources 31: 365-394. http://dx.doi.org/10.1146/ annurev.energy.30.050504.144352

Environment Agency. 2009. Flooding in England: a national assessment of flood risk. Bristol: Environment Agency.

Evans, E. P.; Simm, J. D.; Thorne, C. R. 2008. An update of the foresight future flooding 2004 qualitative risk analysis. London: Cabinet Office.

Forgas, J. 2003. Affective influences on attitudes and judgments, in Davidson, R.; Scherer, K.; Goldsmith, H. (Eds.). Handbook of affective sciences. Oxford: Oxford University Press.

Fuerst, F.; McAllister, P.; Wetering, van de J.; Wyatt, P. 2011. Measuring the financial performance of green buildings in UK commercial property market, Journal of Financial Management of Property Construction 16(2): 163-185. http://dx.doi.org/10.1108/13664381111153132

Gatzlaff, D. H.; McCullough, K. A.; Medders, L. A.; Nyce, C. 2015. The impact of hurricane mitigation features and inspection information on house prices [online]. Available at: http://ssrn.com/abstract=2588892 [accessed 30 March 2015]

Horn, D.; McShane, M. 2013. Flooding the market, $\mathrm{Na-}$ ture Climate Change 3: 945-947.

http://dx.doi.org/10.1038/nclimate2025

IPCC. 2012. Managing the risks of extreme events and disasters to advance climate change adaptation, Special Report of Working Groups I and II of the intergovernmental Panel on Climate Change. Cambridge University Press, Cambridge UK and New York, USA.

JACOBS. 2008. Strategic flood risk assessment. Sheffield. 
James, L. R.; Demaree, R. G.; Wolf, G. 1993. RWG: an assessment of within group interrater agreement, Journal of Applied Psychology 78(2): 306-309. http://dx.doi.org/10.1037/0021-9010.78.2.306

JBA Consultant. 2009. Strategic flood risk assessment. Wakefield.

Kenney, S.; Pottinger, G.; Plimmer, F.; Pocock, Y. 2006. Flood risk and property: impacts on commercial \& residential stakeholders' strategy. College of Estate Management, Reading.

Klein, K. J.; Dansereau, F.; Hall, R. J. 1994. Levels issues in theory development, data collection and analysis, Academy of Management Review 19: 195-229.

Koerth, J.; Vafeidis, A.; Hinkel, J.; Sterr, H. 2013. What motivates coastal households to adapt pro-actively to sea-level rise and increasing flood risk?, Regional Environmental Change 13(4): 897-909. http://dx.doi.org/10.1007/s10113-012-0399-x

Kreibich, H.; Müller, M.; Thieken, A. H.; Merz, B. 2007. Flood precaution of companies and their ability to cope with the flood in August 2002 in Saxony, Germany, Water Resources Research 43(3). http://dx.doi.org/10.1029/2005WR004691

Lamond, J. E. 2008. The impact of flooding on the value of residential property in the $U K, \mathrm{PhD}$ Thesis. Wolverhampton: University of Wolverhampton.

Lamond, J.; Proverbs, D.; Hammond, F. 2010. The impact of flooding on the price of residential property: a transactional analysis for the UK, Housing Studies 25: $335-356$.

http://dx.doi.org/10.1080/02673031003711543

Miceli, R.; Sotgiu, I.; Settanni, M. 2008. Disaster preparedness and perception of flood risk: a study in an alpine valley in Italy, Journal of Environmental Psychology 28(2): 164-173. http://dx.doi.org/10.1016/j.jenvp.2007.10.006

Mundy, B. 1990. The impact of hazardous materials on Property Value, The Appraisal Journal 60(2): 155162 .

Mundy, B. 1992. The impact of hazardous materials on property value: revisited, The Appraisal Journal 60(4): 463-471.

Nichols, W. 2014. Flooding: UK economy among the world's most vulnerable [online]. Business Green Plus. Available at: http://www.businessgreen.com/bg/ analysis/2329570/flooding-uk-economy-among-theworlds-most-vulnerable [accessed 2 October 2014]

O’Brien, K.; Sygna, L.; Haugen, J. E. 2004. A multi-scale assessment of climate change and vulnerability in
Norway, Climate Change 64: 195-225. http://dx.doi. org/10.1023/B:CLIM.0000024668.70143.80

Oppenheim, A. 1992. Questionnaire design, interviewing and attitude measurement. Continuum: London.

Pottinger, G.; Tanton, A. 2011. Waterproof - floodrisk and due diligence for commercial property investment in the UK. $1^{\text {st }}$ ed. Reading: College of Estate Management.

Raaijmakers, R.; Krywkow, J.; van der Veen, A. 2008. Flood risk perceptions and spatial multi-criteria analysis: an exploratory research for hazard mitigation, Natural Hazards 46: 307-322.

http://dx.doi.org/10.1007/s11069-007-9189-z

RICS. 2011. RICS valuation standards - global and UK. $7^{\text {th }}$ ed. Norwich: RICS.

RICS. 2012. Property in the economy 2012: key data and statistics executive summary. London: RICS.

Rose, A.; Krausmann, E. 2013. An economic framework for the development of a resilience index for business recovery, International Journal of Disaster Risk Reduction 5: 73-83.

http://dx.doi.org/10.1016/j.ijdrr.2013.08.003

Rosen, S. 1974. Hedonic prices and implicit markets: product differentiation in pure competition, Journal of Political Economy 82: 34-55. http://dx.doi.org/10.1086/260169

Slovic, P.; Finucane, M. L.; Peters, E.; MacGregor, D. G. 2004. Risk as analysis and risk as feelings: some thoughts about affect, reason, risk, and rationality, Risk Analysis 24: 311-322. http://dx.doi. org/10.1111/j.0272-4332.2004.00433.x

United Nations. 2015. Sendai framework for disaster risk reduction 2015-2030 [online]. Available at: www.preventionweb.net/files/43291_sendaiframeworkfordrren.pdf [accessed 10 April 2015]

Vatsa, K. S. 2004. Risk, vulnerability and asset based approach to disaster risk management, International Journal of Sociology and Social Policy 24(10/11): 1-48. http://dx.doi.org/10.1108/01443330410791055

Wedawatta, G. 2013. Resilience of construction SMEs to extreme weather events, $\mathrm{PhD}$ Thesis. School of Built Environment, The University of Salford, Salford.

Wedawatta, G.; Ingirige, B.; Amaratunga, D. 2010. Building up resilience of construction sector SMEs and their supply chains to extreme weather events, International Journal of Strategic Property Management 14(4): 362-375.

http://dx.doi.org/10.3846/ijspm.2010.27 


\section{APPENDIX 1. Environment agency delineated zones of likelihood of flooding in England}

In England, the Environment Agency flood map shows assessment of likelihood of flooding from rivers and sea. Flood zones 2 and 3 indicate medium and high chance of flooding (medium risk zone- between $1 \%$ and $3.3 \%$ chance of flooding in a given year; high risk zone- greater than and equal to $3.3 \%$ chance of flooding). Flood zone 1 indicates very low to low risk of flooding (between less than $0.1 \%$ to $1 \%$ chance in a given year).

\section{APPENDIX 2. Items for generating market perception on property utility, desirability and marketability (Bhattacharya-Mis, Lamond 2015)}

\begin{tabular}{|c|c|c|}
\hline Theme & Ref & Perception factors (questionnaire statements generated based on the following factors) \\
\hline \multirow[t]{5}{*}{$\begin{array}{l}\text { Property } \\
\text { usability }\end{array}$} & F1 & $\begin{array}{l}\text { Business properties within high and medium flood risk areas will experience more loss of } \\
\text { income as a result of flooding in the future }\end{array}$ \\
\hline & F2 & $\begin{array}{l}\text { Loss of income from flood risk affected properties can negatively affect the demand for such } \\
\text { properties in the real estate market }\end{array}$ \\
\hline & F3 & $\begin{array}{l}\text { Prime location of property is a more important factor in determining property marketability } \\
\text { than flood risk }\end{array}$ \\
\hline & $\mathrm{F} 4$ & $\begin{array}{l}\text { Easier availability of flood insurance can encourage business owners/ occupiers to opt for } \\
\text { insurance against flooding }\end{array}$ \\
\hline & F5 & $\begin{array}{l}\text { Cheaper flood insurance premium for risk prone properties can enhance their desirability in } \\
\text { the real estate market }\end{array}$ \\
\hline \multirow[t]{5}{*}{$\begin{array}{l}\text { Property } \\
\text { desirability }\end{array}$} & F6 & $\begin{array}{l}\text { Once a flood disrupted property loses its value in property market it is difficult to get higher } \\
\text { value for the property again }\end{array}$ \\
\hline & F7 & $\begin{array}{l}\text { Flexible lease terms can positively affect the desirability of risk affected properties in the real } \\
\text { estate market }\end{array}$ \\
\hline & F8 & $\begin{array}{l}\text { Properties having higher expected rate of income generation are more desirable in the } \\
\text { property market in-spite of their high risk of flooding }\end{array}$ \\
\hline & F10 & $\begin{array}{l}\text { Properties with history of reduced value as a result of flooding always have low demand in } \\
\text { the property market }\end{array}$ \\
\hline & F11 & $\begin{array}{l}\text { Investing in mitigation and preparedness measures against flooding can have positive effect } \\
\text { on demand for the property in future }\end{array}$ \\
\hline \multirow[t]{6}{*}{$\begin{array}{l}\text { Property } \\
\text { marketability }\end{array}$} & F9 & $\begin{array}{l}\text { Properties with chances of improved protection against flood risk (installed defence, resilient } \\
\text { measures) are expected to achieve higher value in property market }\end{array}$ \\
\hline & F12 & Installing resilient measures does not affect property value in long term \\
\hline & F13 & More loss of income during flood disruption results in longer recovery time \\
\hline & F14 & Longer recovery time means higher loss of utility and income from the affected property \\
\hline & F15 & $\begin{array}{l}\text { Suitability for mortgage finance makes a property more attractive in the property market in } \\
\text { spite of its high risk of flooding }\end{array}$ \\
\hline & F16 & High flood risk and disruption encourages property occupiers to move out to a lower risk zone \\
\hline
\end{tabular}

